\title{
Managing Environmental and Sustainability Challenges
}

\begin{abstract}
Wicked problems and robust debates abound in environmental policy at local, national and global levels. Over several decades, governments have responded with policies to mitigate industrial pollution, slow the rapid depletion of scarce natural resources and protect biodiversity and ecological systems. The precautionary principle has been invoked to seek thorough assessment of environmental risks before approving economic development projects and technological innovations that might damage ecological assets and human health. Scientific researchers and community groups have lobbied for strong measures to protect biodiversity and promote resilient eco-systems. Resistance to reform has generally been led by conservative parties, corporate media networks and large business firms in traditional industry sectors. Policies for environmental protection have been developed by most national governments, in conjunction with international agreements that encourage collective action. The toolkit of policy instruments has expanded, including regulatory standards and marketbased incentives. The role of scientific expertise in providing policy advice on environmental issues has been vital, but controversial. The chapter explores how science interacts with other sources of knowledge and opinion among practitioners and stakeholders. Climate change policy is analysed as an example of interconnected wicked problems, along with brief references to other environmental issues.
\end{abstract}

(C) The Author(s) 2022

B. W. Head, Wicked Problems in Public Policy, https://doi.org/10.1007/978-3-030-94580-0_5 
Keywords Expertise - Science credibility - Climate change policy · Precautionary principle $\cdot$ Adaptive management $\cdot$ Resilience $\cdot$ Sustainable development

\section{INTRODUCTION}

The challenges inherent in effectively managing sustainability crises and wicked problems have provoked an array of responses in both political and scholarly networks, ranging from malaise, paralysis and denial through to committed advocacy for particular solutions. In academic networks, these challenges have stimulated an increase in problem-oriented crossdisciplinary work - on the basis that the big issues demand a large pool of informed analysis that takes account of diverse perspectives. Many new academic journals have been launched to address these fast-growing fields. But many scientists and other scholars are wary of stepping outside the core themes of their discipline. For example, in the field of public management and public governance, Christopher Pollitt criticised the (limited) extent to which his research colleagues were prioritising the 'grand challenges' of the modern era, and especially the wicked problem of climate change. Pollitt drew attention to many aspects of climate change that warranted public management research, including multi-stakeholder collaborations, making and implementing agreements, long-term planning capability, policy evaluation and public opinion studies (Pollitt, 2015 , p. 184).

On the other hand, the policy sciences have engaged in extensive analysis of environmental policy agendas and the development of new policy instruments (Kettl, 2002). Public policy scholars have analysed the evolution of environmental awareness and advocacy among citizens, stakeholders and the media, and have described how environmental improvement goals became incorporated into governmental policy agendas at local, national and international levels. The historical evolution of problem awareness and policy action has varied in different countries, but some broad patterns can be discerned in how these issues developed. To over-simplify, three main focal areas of environmental concern emerged in the second half of the twentieth century, generated by the pressures of population growth and global demands for economic development. These three focal concerns were the need to reduce all forms of 
industrial pollution, the need to manage scarce natural resources and the need to protect and nurture biodiversity and ecological systems. These problems were initially tackled by local and provincial leaders and advocacy groups, but the broad scale and the political and legal complexities required the involvement of national governments. National governments were more likely to have the resources, information, policy tools and legal authority to undertake regulatory actions. New units of government were established to monitor environmental standards and promote desired outcomes (Rinfret \& Paul, 2019, Ch. 2). An increasing number of community organisations, research centres and think tanks in each country became involved in advancing environmental knowledge and in lobbying for policy improvements (Ascher et al., 2010, pp. 30-34).

Large-scale cross-border problems at an international scale, in turn, have required the involvement of global and regional organisations and networks. Environment programs were established in the United Nations (UN), the European Commission and other international bodies, creating opportunities for negotiating international environmental agreements on a host of topics from biodiversity protection to climate change mitigation. The Montreal Protocol agreement in 1987 to phase out dangerous industrial gases (CFCs) that were destroying the ozone layer is regarded as a relatively successful concerted initiative to reverse the known and urgent risk of ozone depletion (Albrecht \& Parker, 2019). Other international agreements have been more contentious and had mixed results, such as strategies to protect endangered species and to limit global warming. The increasing scale and ambition of UN strategic goals is evident in the Sustainable Development Goals 2015-2030, which encompass 17 interconnected areas including water, energy, food, resource use, climate change, land and marine ecosystems, and a host of human development issues aimed at reducing inequalities and promoting peace (https:// sustainabledevelopment.un.org/sdgs). Policymakers and scholars have recognised that the 'wicked' dimensions of environmental policymaking (complexity, uncertainty and values divergence) require policymakers and researchers to use multi-level approaches for problem analysis, policy design and program implementation. According to Meuleman (2021), public governance should prioritise 'mission-oriented' governance for designing and implementing SDG goals, rather than relying on the 'efficiency' focus of NPM managerialism. 


\section{Integrated Policy Planning or Pluralist InNovation?}

Most analysts suggest that large-scale environmental and natural resources problems are so complex that they benefit from processes that promote policy integration and policy coherence. As noted in Chapter 3, there are strong arguments supporting governance processes that connect multiple stakeholders and service providers. These mechanisms include joined-up government, cross-sectoral collaboration and conflict-reduction processes. Many authors (e.g. Davies et al., 2015; Funtowicz \& Ravetz, 2003; Renn \& Schweizer, 2009) claim that 'inclusive' processes are necessary for the governance of complex risks, in order to enhance the knowledge base, explore uncertainties and accommodate the diversity of value perspectives. Inclusive processes would be required to manage the difficult choices and trade-offs that emerge across goals, values and social constituencies. They note that several types of inclusive processes for discussion and decision are available in democratic societies, and that selecting an appropriate process should take account of the types of issues under consideration and the configuration of stakeholders.

On the other hand, while dialogue among stakeholders and government agencies is generally supported for addressing wicked problems, the quest for 'integrated' policy strategies has been disputed by other groups of researchers (Candel, 2017, 2021). The critics argue that the ideal of 'integration' is a normative position as well as an empirical argument for coordination and interconnected policies. Policy integration, according to the critics, presumes that decision-makers can attain comprehensive knowledge of both problems and solutions, leading towards optimal outcomes - in other words, a holistic approach is presumed to produce 'one best solution'. The alternatives promoted by critics of integration are more pluralistic and decentred. For example, the polycentric selforganising tradition pioneered by Elinor Ostrom argues there are no overarching 'panaceas' (Ostrom, 2007), and that progress can be achieved through a multitude of locally negotiated initiatives in specific communities. This approach has been applied in analysing diverse case studies, ranging from initiatives to protect scarce natural resources (e.g. local communities managing fisheries, forestry and water resources) through to climate change adaptation measures. Polycentric approaches, according to Ostrom, 'facilitate achieving benefits at multiple scales', and also facilitate 'experimentation and learning from experience with diverse policies' 
(Ostrom, 2010, p. 550). Ostrom argued that while the pursuit of international goals and enhanced coordination are indeed important, local and immediate actions are crucial for policy momentum and for achieving positive gains:

Given the failure to reach agreement at the international level on efficient, fair, and enforceable reductions of greenhouse gas emissions, continuing to wait without investing in efforts at multiple scales may defeat the possibilities of significant abatements and mitigations in enough time to prevent tragic disasters. (Ostrom, 2012, p. 354)

Another decentred approach that rejects the quest for rational 'optimal' solutions is anchored in the cultural theory of Mary Douglas and her colleagues (Douglas \& Wildavsky, 1982; Thompson et al., 1990). Cultural theory claims there will always be diversity in citizens' perspectives about issues, and diversity in their preferences for action. This is because social preferences are grounded in four different ways of thinking (worldviews) about social order and social change: hierarchy, individualism, egalitarianism and fatalism (Verweij \& Thompson, 2006, p. 3). These alternative ways of perceiving the world are frames or lenses which broadly shape people's preferences about social arrangements and their approach to how problems should be managed. Cultural theory argues that these four perspectives are entrenched, and therefore it is sensible for policy-makers to support a pluralist approach that sustains a range of 'clumsy' and 'messy' solutions - this approach seeks to avoid privileging any one of the four perspectives over the others. Policymakers can work with a variety of policy processes and a mix of policy instruments that take account of these different preferences of citizens. In other words, tackling complex problems requires flexible combinations of approaches to problem-solving (Ney \& Verweij, 2015; Verweij \& Thompson, 2006). More generally, psychologists have argued that effective communication and persuasion should recognise the key values and terminology associated with the various cultural worldviews, and therefore frame policy arguments in ways that align with such orientations (Kahan \& Braman, 2006). Steven Ney sums up the cultural divergence perspective by linking it to problem framing. He suggests that groups of individuals 'use frames to tell plausible and convincing stories ... they are selective accounts and specific interpretations of messy issues. Each story then is potentially contestable by someone who looks at the same problems through the 
perceptual lens of a different frame and comes to divergent conclusions' (Ney, 2009, p. 180). Numerous studies have shown that problem frames and narratives communicated by experts and political leaders are regarded as more credible when aligned with the views of citizens, and framing is more influential in reinforcing views than in changing them (Lachapelle et al., 2014).

\section{SCIENCE AND THE CONSTRUCTION of Environmental Policy Issues}

Environmental challenges are the meeting place between science, politics and complex social-ecological systems. Scientific networks and institutions had already recognised the 'human causes' of major environmental changes by the 1970s, when the UN Environment Program commenced its work and many governments began to establish environment protection agencies. Calls for policy change became more frequent and urgent in the 1980s (Brundtland, 1987; National Research Council, 1992). In reviewing some decades of experience, Selman noted that despite greater scientific knowledge and the roll-out of diverse environmental programs, progress in achieving improved outcomes was likely to be patchy and iterative:

In practice, despite enormous amounts of dedication and inspiration, environmental planning only ever achieves partial success. This is due to the 'wickedness' of environmental issues, deriving not only from their technical complexity, but also from the multiple arenas where they are contested and debated. As capacities are built to overcome one barrier, another one arises; as progress is made towards sustainability, so the finishing line recedes. (Selman, 1999, pp. 168-169)

All environmental issues have a very strong reliance on scientific information about trends, causes and impacts. Scientific findings are used by policymakers and stakeholders to support their analysis of problems, assess the severity of impacts and evaluate possible options for improvement. However, as shown in many case studies, while science is a necessary ingredient in the consideration of environmental policy issues, the framing, scoping and prioritising of issues is always political and often controversial. The construction of competing causal stories is a central feature of policy debate, along with processes for stakeholder and citizen 
'voices' to be heard. Green community organisations and advocates of participatory democracy are concerned that civil society organisations might be excluded if environmental 'modernisation' leads to the 'scientisation' of environmental decision-making, e.g., through over-reliance on technocratic metrics and trade-offs. For green activists, citizens and social movements must be involved to express their own values and contribute to local solutions (Bäckstrand, 2003; Fischer, 2017). Champions of civic collaboration and citizen science argue that this approach can help to generate significant improvements in addressing wicked problems such as climate change, extreme poverty, pandemics, health inequalities and natural disasters (Hodgkinson et al., 2021).

Science optimists hope that, despite political disputes about problem framing, scientific knowledge can make major differences in decisionmaking, especially when science is complemented by practical lessons drawn from stakeholder experience of 'what works'. But scientific knowledge of trends, causes and impacts is not sufficient to shape difficult environmental issues. Drawing on the management and leadership literature, Heifetz (1994, p. 76) distinguished among three situations: first, where there is clarity about both the nature of the problem and the likely solution; second, where the nature of the problem is clearly discerned, but the solutions are not-typically leading to further investigation and discussion; and third, situations where both the problem definition and the solution are unclear, requiring extensive discussion and debate over time. In short, some issues are more likely to become 'wicked' when the quality and coherence of the knowledge base interact with the conflicting perspectives and values of stakeholders (Alford \& Head, 2017, p. 403). Balint and colleagues suggest that distinguishing between different problem-types is fundamental for constructing effective environmental policies and natural resource management programs. Decision-makers can better appreciate the diverse challenges of policy development if the range of stakeholder values has been mapped and if the knowledge base available to governmental and other stakeholders has been assessed as relatively robust or as requiring major improvements (Balint et al., 2011, p. 10). Different forms of cooperation and collaboration will be required to develop environmental policy strategies, taking account of these dynamics around problem framing, knowledge and values.

Weible (2008) summarised the policy studies literature by arguing that expert-based information tends to be used in three ways: instrumental, 
learning and political uses. However, these three uses are likely to occur in different ways across various policy fields. These patterns will depend especially on two sets of factors-(1) the degree of openness/closure (e.g., closed sub-systems with a few powerful participants generally exhibit a higher level of agreement on problems and approaches); and (2) the gap between adversarial positions in contested policy spaces (e.g., differences can be amplified by partisans selectively relying on aligned experts). In some circumstances, there may be opportunities for developing shared knowledge (e.g. the experience with natural resources management) and for reducing conflict through collaborative forums (Weible, 2008, pp. 627-8). However, a study of joint knowledge production in Dutch water management found that alignment between experts and policy bureaucrats was more likely to occur than with other groups of stakeholders. According to that study (Edelenbos et al., 2011, p. 683), the three groups - experts, bureaucrats and other stakeholders-use 'different norms and criteria for knowledge production, ranging from scientific validity (experts), policy usefulness (bureaucrats) and social validity (stakeholders)'. In most research on policy debates, it has been found that expert knowledge is harnessed to reinforce or legitimate the existing beliefs of participants rather than generate policy learning or new perspectives. Empirical studies have shown how patterns of usage are linked to institutional structures affecting policy, the nature and origin of the information, the value placed on knowledge and the dynamics of policy conflict (Heikkila et al., 2020, p. 536).

The scholarly literature on the utilisation of scientific research in policymaking generally presumes that best-available evidence should be used to inform policy debates (Head, 2010b, 2016). This literature places a high premium on the perceived quality and relevance of expert knowledge. However, most decision-makers, stakeholders and the general public are unfamiliar with the rigorous methods of scientific research. Importantly, they are much more interested in the sources of policy-related information and the implications of the policy narratives. This leads to a strong focus on the reputation and perceived independence of particular experts. The classic article by Cash and colleagues outlines a threefold schema:

... scientific information is likely to be effective in influencing the evolution of social responses to public issues to the extent that the information is perceived by relevant stakeholders to be not only credible, but also salient and legitimate. In the sense used here, credibility involves the scientific 
adequacy of the technical evidence and arguments. Salience deals with the relevance of the assessment to the needs of decision makers. Legitimacy reflects the perception that the production of information and technology has been respectful of stakeholders' divergent values and beliefs, unbiased in its conduct, and fair in its treatment of opposing views and interests. Our work shows these attributes are tightly coupled, such that efforts to enhance any one normally incur a cost to the others. (Cash et al., 2003, p. 8086, emphasis in original)

This perspective assumes that the perceived quality of scientific research findings is very important. However, this approach tends to overlook the significance of cultural cognition research about the polarised use of expertise, as demonstrated in the climate debate. For example, Kahan (2016) shows that 'politically motivated reasoning' serves to filter information in ways that reinforce pre-existing beliefs. Expert knowledge is not perceived as neutral; sources identified as agreeing with the proponent are seen as more trustworthy. In a similar manner, this cherry-picking bias is explained by Jones (2011) through cultural cognition theory, arguing that the difficulties of persuading citizens about the challenges and responses to climate change are not open to rational solutions. These disagreements cannot be resolved simply through 'more science'.

The appropriate roles for scientists in social and environmental policy debates and in provision of policy advice have been long discussed by scholars and commentators (Ezrahi, 1980, p. 118; Owens, 2016). Even when scientists largely agree on what counts as reliable knowledge, they are divided about their appropriate roles in advising policymakers on the mix of required policies and highest priority investments. These tensions have been evident in the reception of the scientific work of the International Panel on Climate Change whose reports include both scientific modelling and a summary of implications for policymakers (IPCC, 2018, 2021). While most agree that scientific findings should be taken into account, the view that scientific knowledge can and should shape policymaking is strongly resisted. According to one critic: 'We are asking science to do the impossible: to arrive at scientifically coherent and politically unifying understandings of problems that are inherently open, indeterminate and contested' (Sarewitz, 2017).

Roger Pielke (2007) has argued that scientists should beware of crossing the line from objective analysis to policy advocacy, because policy preferences do not follow tightly from scientific findings-except in 
narrow technical matters where there are no trade-offs or value choices at stake. Most scientific advice should take the form of providing objective responses to questions and providing options analysis where requested by authoritative decision-makers (the 'honest broker' role). Pielke warns that scientists who choose to become policy advocates will risk undermining their own scientific credibility, and they should campaign on the basis of explicit values rather than pretend to be espousing pure science. Most commentators in science policy now recognise the nexus between values, politics and science, and accept that a science-first approach is unrealistic (Weber et al., 2017; Weible \& Moore, 2010).

Scientific advice is commonly associated in the public mind with expert advisory bodies and policy development processes. There are numerous examples of researchers being invited to be members of expert panels or making expert submissions to inquiries. The purposes, composition and longevity of such expert advisory bodies vary widely (OECD, 2015; Owens, 2012). Government agencies often create specialised units that employ skilled researchers, who do not necessarily undertake new or original research but who can be crucial in translating governmental and external research findings as part of the briefing process for senior executives, ministers and legislators. In some policy fields, expert standing committees (usually with a majority of external members) may provide advice on quality standards, risk parameters, cost-effectiveness and so on. Ad hoc expert bodies may be formed to respond rapidly to contemporary crises; the most formal of these are public inquiries or royal commissions. Legislative committees also undertake inquiries on a range of social, environmental and technical topics, and usually consider the submissions of experts and stakeholders concerning current and emerging policy challenges.

Scientific analysis and advice inform the policy advisory process rather than determine the strategic direction of environmental policy and the selection of specific regulatory instruments. Scientific knowledge is fundamental for assessing the nature of risks and harms (problem definition), and thus for assigning higher priority and urgency to the issue (agenda-setting). In many areas of environmental concern, the findings of scientific research and evaluation have been consolidated into standards and performance metrics that are useful for practitioners. For example, in relation to biodiversity conservation and the vital role of nature reserves for protecting wilderness and habitat, the International Union for Conservation of Nature (IUCN) has produced standards and principles for the 
effective planning and management of World Heritage areas, national parks and other conservation areas (IUCN, 2017).

While the knowledge base for environmental issues has continued to grow in depth and breadth, with some issues being thoroughly researched, many other issues suffer from lack of significant long-term research and evaluation. This is especially the case with emergent challenges driven by biotechnologies and novel resource extraction technologies. International organisations and science networks help to improve the knowledge base by sharing and comparing information. For policy scholars, research into public debates about contested priorities and policy choices can demonstrate the extent to which stakeholders agree about the quality and coherence of reliable knowledge, and the extent to which the competing policy narratives are framed by fundamental conflicts in values and stakeholder interests.

\section{Managing Risks-Precaution, Resilience AND ENVIRONMENTAL STANDARDS}

An important threshold question in environmental policy is whether governments should take a precautionary approach to managing environmental risks. This is especially important when knowledge of causes and impacts is uncertain and incomplete (Martuzzi \& Tickner, 2004; Ravetz, 2004). There have been fierce disputes about the circumstances in which precaution should be invoked to constrain or hinder technical innovations and commercial investments. The onus of proof concerning the risks of technical and commercial innovation could be allocated in either of two directions - either to support commercial business interests (i.e., innovation is supported and encouraged unless there is robust evidence of harm) or to support environmental integrity and health (i.e., innovations are not licensed unless the balance of harms and benefits has been carefully assessed as favourable or unless appropriate conditions and regulations have been implemented). The Rio Declaration on Environment and Development in 1992 declared (Principle 15):

In order to protect the environment, the precautionary approach shall be widely applied by States according to their capabilities. Where there are threats of serious or irreversible damage, lack of full scientific certainty shall not be used as a reason for postponing cost-effective measures to prevent environmental degradation. 
The precautionary principle has been invoked to minimise harm in a wide range of situations. Examples include regulatory restrictions on the use of novel technologies (such as genetically modified organisms (GMOs) in agriculture, or new pharmaceutical drugs in medical therapy); and licences or approvals have been withheld for industrial projects that could cause irreversible harm to ecological systems. Business lobbyists argue that entrepreneurs should be encouraged to invest in innovation and that the onus should be on regulators to prove the probability of serious harm. By contrast, the precautionary principle is more conservative than permissive. High-risk threats to human health and natural systems should not be authorised unless scientific research demonstrates there are no long-term adverse impacts (Metz \& Ingold, 2017; Stirling, 2008; Van Asselt \& Vos, 2006). Political lobbying on where to draw the line in particular cases has been intense.

In situations of rapid change or crisis that threatens natural assets, the question arises about whether the policy goal should be modest or ambitious-for example, is the goal simply to avoid further harmful deterioration in ecological conditions, or is the goal to 'restore' the previous superior level of the ecological system? Another approach, which also eschews restoration, is to identify the few remaining areas of relatively 'intact' or pristine ecological systems and to urge highest priority for preserving and protecting such areas (Plumptre et al., 2021). The environmental science literature canvasses debate about which standards of environmental integrity should be pursued in various situations, while increasingly accepting that policy decisions will be highly political and will be shaped by arguments about balance, feasibility and cost-effectiveness.

The ecological 'resilience' literature tends to argue that high standards of environmental protection are required, but that 'restoration' is not a realistic possibility within an evolving set of systems and sub-systems (Gunderson \& Holling, 2002). Resilience is generally understood as the capacity of a system to 'absorb disturbance' and reorganise in ways that retain its functions and structures and interactions (Walker \& Salt, 2006). The UN Disaster Risk Reduction group defines resilience as follows:

Resilience is the ability of a system, community or society exposed to hazards to resist, absorb, accommodate, adapt to, transform and recover from the effects of a hazard in a timely and efficient manner, including through the preservation and restoration of its essential basic structures and function. (https://www.undrr.org/terminology) 
This scholarly literature emphasises the importance of understanding adaptive relationships within social-ecological systems, taking account of the 'robustness' of sub-systems and their 'nested' levels of interaction (Anderies et al., 2013). The related literature on 'adaptive governance' for social-ecological resilience (Chaffin et al., 2014) highlights the importance of building skills and capacities at every level to respond effectively to changes in complex systems. There is a key role for social learning by stakeholders, scientists, decision-makers and their networks.

Another strand in resilience literature has examined the capacity of communities to recover from disasters and from entrenched environmental crises. The central focus is how to support and strengthen 'adaptive capacity, self-organisation and agency' at the level of local communities and their wider networks (Berkes \& Ross, 2013; Goldstein, 2012). The concept of resilience has also been taken up in studies of public administration and policymaking. The OECD (2014) has highlighted the relevance of this conceptual literature for a deeper understanding of how governments could use risk management and adaptive management in addressing dynamic and turbulent situations. Others have cautioned against over-emphasising flexibility and adaptive capacity at the expense of other important public sector values such as stability, predictability, reliability and efficiency (Duit, 2016).

\section{WICKED DIMENSIONS of Environmental Policymaking}

Environmental policy analysis and the political debates on environmental policymaking have recognised the fundamental importance of complexity, uncertainty and stakeholder disagreement. Many researchers have described the 'wicked' features of environmental case studieswhether in food and agriculture, biodiversity, land management, resource extraction, climate change, air and water quality, renewable energy and so on. Environmental policy research highlights both the enduring challenge of wicked problems, and the enduring significance of 'wickedness' as a frame for policy analysis (e.g. Durant \& Legge, 2006; Turnpenny et al., 2009). For some scientists there is continued disappointment that politics seems to prevail over scientific knowledge. However, other researchers have emphasised that in democracies it is necessary to build trust through transparent processes to mediate differences in goals and perspectives, 
working across the boundaries of science, stakeholder interests and political processes (Hajer \& Wagenaar, 2003).

Researchers suggest the importance of both the vertical dimension of public authority and the horizontal dimension of inclusive dialogue. Taking this dual approach, researchers suggest that unpacking the intractable or intransigent nature of the problems would require wide discussion through networks and collaborative forums. Pahl-Wostl and colleagues have argued that a structured analytical framework is a necessary element for inclusive analysis of the complex and multi-facetted aspects of environment policy coordination (Pahl-Wostl et al., 2020). Such an approach would facilitate identification of multiple pathways that could lead to an improvement (or a decline). On the other hand, analysis and engagement are not enough; effective interventions to tackle the substantive problems would additionally require strong governmental regulation, coordination and leadership (Crowley et al., 2020; Peters, 2019).

Complexities abound, owing to the different levels or scales of behaviour (e.g. local, regional, global, cross-border issues); the interconnections between various socio-economic and ecological issues (e.g. power, poverty and resource use); and the large number of organisations and institutions that play a role in policy debate and program implementation. Many types of uncertainty also abound (Bammer \& Smithson, 2008), posing challenges for understanding the nature and impact of the problems and for designing or negotiating appropriate policy responses. Van Bueren et al. (2003) interrogated the nuances of wicked environmental issues in terms of the varying effects of cognitive, strategic and institutional uncertainties. Actors with divergent perspectives have difficulty in working together. The conclusion was that the uncertainties underlying and shaping wicked problems can be reduced only through network-based 'cooperation', thereby 'enhancing and intensifying interactions between stakeholders' (2003, pp. 193-194, 211). Dewulf and Biesbroek (2018) developed a detailed schema for classifying types of uncertainty. On one dimension, they distinguish between uncertainties arising from knowledge gaps, conflicting values and frames of stakeholders, and the underlying 'unknowns' concerning the behaviour of complex systems. On a second dimension, they focus on processes for debate and decision, identifying three related uncertainties about the rules of the game, the likely tactics of other actors and the concrete content of policy choices. 
Brugnach and colleagues argue that a focus on reducing knowledge gaps is not enough, and that it is essential to recognise the importance of multiple frames through which stakeholders understand the problem and possible solutions (Brugnach et al., 2011). Uncertainty should be not seen as primarily about 'the facts' but as embedded in the divergent interpretations, relationships and sense-making of the various participants:

because it is from this understanding that problems and solutions emerge. Under this view, solutions do not exclusively consist of eliminating or reducing uncertainty, but of reframing the problems as such so that they convey a different meaning. (Brugnach et al., 2008, p. 1)

The future-oriented policy sciences, which assist in setting realistic goals for climate response policy, have to absorb difficult pressures to maintain their credibility and relevance. On the one hand, reliable long-term forecasts are needed to underpin incentives for investment in low-emissions technologies; but on the other hand, uncertainties about the pace and direction of change require flexibility and rapid adjustments to new information (Nemet et al., 2017).

\section{Climate Change as a Wicked Policy Arena}

The argument that we have entered the era of the Anthropocenewhere industrial activities are undermining the planetary systems on which human societies depend-is intended to galvanise urgent action to arrest the deterioration of natural assets, by ensuring that governments and citizens take responsibility for inclusive remedial action at every level (Biermann, 2014; Ison et al., 2018; Lövbrand et al., 2020). The argument is that the pace, scale and depth of change have intensified, leading to cascading negative impacts on interconnected systems (Hom \& Penn, 2021). The recent wave of declarations that all societies are facing a climate emergency is intended to galvanise strategic priorities to focus on avoiding future catastrophe; but the political rhetoric of climate emergency could also spark further polarisation and resistance (Patterson et al., 2021). Political leadership is required to ensure that ecological system goals are prioritised. In the past, policymaking on major issues has involved trade-offs between social, economic and environmental objectives, with economic interests generally dominant. Climate change 
has become the major crisis that highlights these concerns about rethinking priorities and managing competing objectives. The large and rapid nature of planetary change could even increase the political difficulties of shifting priorities towards environmental goals (Dryzek \& Pickering, 2019, p. 98).

The planetary scale of the Anthropocene perspective has also encouraged techo-engineering proposals to 'save the planet' (Lomborg, 2010), including solar heat shields, the capture and storage of industrial emissions, and various initiatives for genetic reengineering of plants and animals. However, while some of these proposals may prove to be technically feasible, the environmental and ethical dimensions of identifying and managing the associated risks have not been canvassed (Reynolds, 2021).

There are several reasons why climate change response policy can be termed a field of 'wicked problems' (Head, 2014). Firstly, the climate change challenges are actually a series of linked problems, none of which can be resolved in isolation. The interconnections between the UN Sustainable Development Goals illustrate these crucial inter-dependencies. Progress in one field may depend on parallel progress elsewhere, and negative developments in one area may undermine initiatives in other fields. Spillover or ripple effects are common. For example, a transition away from fossil fuels can reduce greenhouse gas emissions, but threats to biodiversity would be exacerbated if the 'solution' is to clear old-growth forests in order to expand the farming of crops that produce bio-fuels (Portner et al., 2021). Rural areas are often the subject of competing land uses, some of which involve competing forms of legitimacy, such as the overlay of commercial interests in areas formerly governed through traditional entitlements. Sayer et al. (2013) have suggested some procedural principles, including adaptive management and inclusive participation, which could assist in large-scale processes for reconciling agriculture, conservation and other competing land uses.

Secondly, future-oriented estimates of the costs and benefits of specific interventions - directed at tackling climate change and promoting sustainable development - are likely to be diverse, uncertain and shift over time and place. Policy responses need to account for both short-term and longterm trajectories and adapt to the constantly changing contexts. Thirdly, the risks and impacts are simultaneously local, regional and global. This multi-level diversity makes the understanding of impacts, and the choice of adaptive responses, very difficult. The underlying systemic causes can manifest in specific local symptoms (such as famine and crop failures 
during cycles of drought or flood devastation in large river-delta cities). Fourthly, despite the solidity of the scientific knowledge base, key findings have been hotly contested in public debate, with scepticism and denial being promoted by some industry sectors, especially in relation to the extent of climate change and the human contribution to causality. Hence, fifthly, the allocation of responsibilities and the 'ownership' of change leadership has remained unresolved, and the urgency of change has been widely resisted by particular governments, corporations and political groups. This is true both within each country (industries, localities) and across groups of countries (developed, developing, small, large, etc.). In a polycentric system of governance, there are opportunities for both separate and joined-up initiatives. For example, in the absence of policy leadership by the US national government, 25 state governments formed the US Climate Alliance, which encourages policy innovation and investment to advance the agendas of climate change mitigation and adaptation.

Sixthly, there are significant equity issues and moral concerns around impacts and burden sharing. These conflicting perspectives reinforce the polarisation of policy debates. Examples include the argument that poor and vulnerable populations will suffer more from the harmful impacts of climate change; that poor nations should receive special incentives and assistance to make the necessary transitions; and that future generations should not suffer as a result of current inaction and selfishness. Finally, the impetus to prioritise climate action has been slowed in the wake of the global financial crisis and the global pandemic crisis; in particular, a resurgence of economic nationalism and protectionism has hindered international collective action, exacerbated by government leaders having a reduced appetite for shouldering further adjustment costs.

Taken together, these 'nested' problems constitute what Garnaut (2008) has called a 'diabolical' challenge for science and for politics, and what Lazarus (2009) called a 'super-wicked' problem for political and legislative resolution. In the same vein, Levin and colleagues asserted that the 'super-wicked' nature of climate change policy has produced a 'tragic' impasse, because 'time is running out; those who cause the problem also seek to provide a solution; the central authority needed to address it is weak or non-existent; and, partly as a result, policy responses discount the future' (Levin et al., 2012, p. 123). Psychological research has shown that discounting the future is common. Citizens and legislators generally prefer the current (and familiar) array of benefits/rewards over the 
likely costs of mitigating future (but unknown) harms through substantial policy reforms and major behavioural changes. This cognitive process of 'discounting' future risks is likely to undermine the rational cost/benefit proposition that any further delay in substantially reducing greenhouse gas emissions will generate massive additional costs for remediation that will confront future leaders, stakeholders and citizens (Giddens, 2011; Stern, 2007).

Given that global warming is linked to the scale and composition of industrialisation, the pace of global industrial development has been massive. For example, the consumption of energy in India doubled between 2000 and 2020 and $80 \%$ of its energy production utilised carbon-intensive sources (IEA, 2021, p. 11). China recently accounted for half of global coal consumption and $29 \%$ of global energy-related carbon emissions (Zhou et al., 2020).

The debate on climate response policy has highlighted the differences between those who deny there is a major problem, those who seek incremental policy adjustments, and those who urge rapid and ambitious transformations. In many cases, the policy action has focused on small tangible steps to manage the symptoms of a broader evolving crisis. Examples include changes in building codes to ensure that urban infrastructure can better withstand storms, floods, fires and other natural disasters; and increased investment in emergency response capabilities. The more ambitious strategies aim at rapid reductions in the emission of greenhouse gases through a mix of incentives, standards and regulations that facilitate transition to new technologies and industry practices. Dewulf (2013) found major differences in policy framing between the mitigation and adaptation perspectives. Mitigation strategies prioritise the reduction of greenhouse gas emissions (e.g. the goal of 'zero net emissions' and phasing out 'carbon-polluting' industries), whereas adaptation strategies focus on adjusting to the likely ongoing effects of climate extremes and natural disasters. Dewulf also found that the framing of perceived threats from climate change was sometimes presented as 'external' security threats (e.g. the influx of displaced persons or 'climate refugees') rather than focusing on the need to protect the health, well-being and livelihoods of citizens. Adaptation policies have become more readily accepted as mainstream priorities because they are seen as practical necessities in the face of tangible disruptions caused by droughts, fires, storms and floods (Adger et al., 2009; Schipper \& Burton, 2009; Wise et al., 2014). By contrast, emissions reduction (or mitigation) strategies have been seen as 
more challenging and have been strongly resisted by incumbent industries and conservative political groups.

Substantive differences on climate policy are evident between those who champion technocratic engineering solutions (e.g., projects to deflect solar radiation or facilities to capture and bury carbon emissions), and those who seek a mix of regulatory and behavioural incentives to foster renewable energy and low-emissions industrial processes. Lomborg (2016) has argued that government leaders' pledges in 2014-2015 to reduce emissions by over $30 \%$ by 2030 would not only be expensive, but would fail to reverse global warming this century. Industry-friendly economists (and critics of 'alarmist' green politicians) have generally rejected carbon pricing schemes, instead recommending investment in technical projects, geo-engineering and energy R\&D (Lomborg, 2010, pp. 381, 395). More recently, however, Lomborg has argued that carbon pricing could actually be a useful policy instrument for nudging economic change, but that the main thrust should remain with R\&D for technology innovation, together with very large investments in adaptation measures for urban infrastructure and food security (Lomborg, 2020).

Climate policy preferences are tied to how people perceive the problems and their affinities with various styles of thinking. Policy research consistently shows that preferred solutions tend to be shaped by the way that problems are framed or constructed, including the way that values are mobilised by leaders and stakeholders (Peters, 2005). The framing of a complex set of issues like climate change occurs at several levels. The cognitive dimension is primarily about science, knowledge and policy ideas; the communicative dimension focuses on how messages are circulated, challenged or reinforced; the organisational or institutional dimension centres on embedded practices, rules and routines, and capacities for implementation; and the political dimension is about power, crisis management and political leadership to defend or change policies and practices. Framing of climate change response strategies should recognise these four dimensions. In doing so, policy actors need to understand the values and concerns of the public-communication with diverse stakeholder audiences needs to be nuanced and use appropriate language. The research on effective science communication has been radically revised in the light of environmental debates (Corner \& Clarke, 2017; Lakoff, 2010; Turnpenny, 2012), and increasingly recognises the diversity of values across multiple audiences (Jamieson et al., 2017), as foreshadowed in theories of political-cultural segmentation. There is some evidence that 
framing the policy reform issues in economic terms can often be more persuasive than relying on the credibility of climate science projections (Cann, 2021).

\section{Using Collaborative Approaches For ENVIRONMENT POLICY}

Democracies usually display a pluralistic divergence of viewpoints. Because it is not possible to resolve environmental policy disputes through 'more science', policy leadership and engagement processes need to take account of divergent interests at local and regional levels, and across industry sectors. Many areas of environmental policy and natural resource management have been regarded as wicked problems whose levels of complexity and conflict can only be managed effectively through drawing upon collaborative approaches (DeFries \& Nagendra, 2017; Head et al., 2016).

Critics of contemporary policymaking argue that the standard managerialist approaches of modern government, along with the 'technocratic scientisation of public policy', cannot effectively address the wicked social, economic and ecological issues of modern societies (Fischer, 2003; Frame \& Brown, 2008). Performance metrics and standards are vital, but multi-stakeholder discussion processes are necessary to articulate and mediate the differences in values that underlie policy disagreements. Ideally this could lead to constructing a better-informed basis for broad agreement on longer-term goals and medium-term policy initiatives.

Policy and planning processes for environment and natural resources have shifted over time towards higher levels of engagement and cooperation with stakeholders at local and regional levels. To take an example that has been thoroughly researched in the USA, the regulation of watersheds (or river basins) was traditionally the responsibility of specific functional agencies, but the planning arrangements have gradually been opened up to multiple stakeholders and the general public. This shift was partly due to pressures from stakeholders and partly due to the persistence of underlying problems such as water quality, biodiversity conservation and protection of coastal areas. The involvement of stakeholders led to a variety of more cooperative arrangements for managing water and natural resources (Wondolleck \& Yaffee, 2000). Moreover, the emergence of network organisations has enabled the rise of knowledge-brokering functions, which increase the flows of information relevant to specific environmental issues (Michaels, 2009). Stakeholder involvement has also 
been championed in the emerging environmental research literature on co-production and co-design (Miller \& Wyborn, 2020).

Experience with more inclusive and networked models in some issueareas has been encouraging (Goldsmith \& Kettl, 2009), but many practical difficulties have emerged in attempting to use more inclusive approaches for tackling complex interconnected problems (Koontz \& Thomas, 2006). On the one hand, improving dialogue between conflicting stakeholders has been seen as 'good politics', but on the other hand, it was less certain that positive environmental outcomes were being achieved. Paul Sabatier's research team raised some tough issues:

Many of the "solutions" reached in collaborative stakeholder settings may be good political compromises, but they do not really solve the environmental or socioeconomic problems plaguing a watershed. Conversely, many negotiated solutions may be appropriate from a physical environmental standpoint, but they may leave out key stakeholders who will pursue other avenues of blocking implementation. Many collaborative efforts create policies that rely on voluntary cooperation without any formal legal enforcement mechanisms, which often creates considerable doubt about the likelihood of policy implementation. (Sabatier et al., 2005, pp. 5-6)

Thus, watershed management forums were sometimes criticised for being politically symbolic arrangements which distracted attention from ongoing water management problems. At the same time, however, inclusive processes provided the opportunity for addressing the social interaction dimension of complex problems. Sabatier's team reviewed the evidence about factors that facilitate the formation of more collaborative arrangements and increase the likelihood of producing positive results. While recognising that the US institutional and political culture is different from elsewhere, they suggested that multi-stakeholder agreements are more likely to be successful when there is a pressing need to overcome gridlock or stalemate; when all major stakeholders are included; and decisions are made through consensus. The convenor would ideally be a 'respected, knowledgeable and neutral' person, and network members should stay personally involved and committed to longterm discussion (Sabatier et al., 2005, p. 197). Building trust and respect among network members is always seen as important, but there are also practical benefits in finding the 'right' mix of membership (Ansell et al., $2020)$. 
There is a large literature on 'collaborative' governance and the benefits of organisations working across sectoral boundaries (Weber \& Khademian, 2008). Collaborative processes may contribute to better information and lead to innovative solutions (Ansell \& Torfing, 2014; Sørensen \& Torfing, 2021). The modern literature on interactive governance and stakeholder engagement confirms the empirical trend towards cross-sectoral relationships and interdependence, and there is an increasing number of research studies exploring the conditions under which partnerships and network forums can be successful (Douglas et al., 2020). But inclusive discussion in the policymaking process has arguably fallen short of fully 'collaborative' approaches. This is because, unlike cooperation and coordination, full collaboration requires genuine powersharing (Keast et al., 2004), and such devolution of power has been a step too far for most public agencies.

Two important caveats have emerged. Firstly, collaboration is not just about achieving consensus; effective problem-solving and effective program management require a clear focus on goals and strategic directions. Secondly, while stakeholders in industry and community are crucial, the overarching role of public authority remains vital for effective problem-solving and implementation (Crowley et al., 2020; Pierre \& Peters, 2005; Torfing et al., 2012). In addition to their regulatory and coordination roles, government agencies are also vital for monitoring trends, and adjusting the flow of policy advice as circumstances evolve; these roles are required for responding to slow-onset deterioration in environmental conditions (Tosun \& Howlett, 2021).

One of the processes recommended for enhancing the sharing of knowledge and developing shared goals is the use of mediation and dispute resolution techniques. This is a specialised area of professional skills. It is widely seen as valuable for managing and mitigating social and environmental conflicts (Lewicki et al., 2003; O'Leary \& Bingham, 2003; O'Leary et al., 2004). The argument is that wicked problems can be better managed (though not magically cured) by exploring and mediating divergent perspectives through a process of dialogue and deliberation. This process can also facilitate consideration of the inherently difficult choices about priorities and trade-offs.

The other major process that can empower and complement collaborative forums is the mobilisation of governmental administrative resources. For example, public sector coordination is generally necessary to focus organisational effort on the strategic goals enunciated by government 
leaders, who in some cases might build on the agreements forged in multi-stakeholder forums. Whole-of-government approaches and 'joinedup' government strategies are often needed to align the resources of diverse agencies to the announced priorities of government. Inter-agency coordination through 'joined-up' government is a common challenge for addressing many complex problems. The broader challenge is to establish effective cross-sectoral arrangements to bridge the vast divide between public sector agencies and the various non-government spheres represented by business, community and research organisations (Torfing et al., 2012). Framework agreements can provide a useful instrument for harnessing the activities of key actors within government, across levels of government and across other sectors. For example, in the European Union, complex environmental issues have been tackled through agreements such as the Water Framework Directive in 2000, which established principles for integrated water basin management but allowed flexibility in implementation according to local contexts. Similarly, the EU Waste Framework Directive in 2008 laid out targets for waste reduction and resource recovery while recognising the need for local variations.

In conclusion, the toolkit of environmental policy instruments has expanded greatly, taking into account the wide variety of issues, their locations, and the capacities of governments and other policy actors. Legislation to establish environmental agencies, regulatory standards and data-bases for monitoring and evaluation have significantly increased capability and awareness. Over time, business entrepreneurs have developed new technologies for green transitions, and governments have experimented with pricing, taxation and market-based incentives to leverage pro-environment behaviour. The innovation agenda is further discussed in later chapters. 
Open Access This chapter is licensed under the terms of the Creative Commons Attribution 4.0 International License (http://creativecommons.org/licenses/ by $/ 4.0 /$ ), which permits use, sharing, adaptation, distribution and reproduction in any medium or format, as long as you give appropriate credit to the original author(s) and the source, provide a link to the Creative Commons license and indicate if changes were made.

The images or other third party material in this chapter are included in the chapter's Creative Commons license, unless indicated otherwise in a credit line to the material. If material is not included in the chapter's Creative Commons license and your intended use is not permitted by statutory regulation or exceeds the permitted use, you will need to obtain permission directly from the copyright holder.

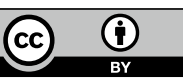

